hyperinsulinism can explain this, as insulin may be critical in the control of the secretion of insulin like growth factor I.' Interestingly, high concentrations of this growth factor have been found in patients with progressive exudative lesions.

Our findings suggest that growth hormone is not essential for the initiation and development of diabetic retinopathy. Our patient's normal concentrations of insulin like growth factor I and her growth hormone deficiency emphasise the role of local growth factors in the development of this complication of diabetes.
Merimee TJ, Zapf J, Froesh ER. Insulin like growth factors: studies in diabetice with or without retinopathy. $N$ Engl F.Med 1983;309:527-30.

2 Rabin D, Bloomgarden ZT, Feman SS, Davis TQ. Development of diabetic complications despite the absence of growth hormone in a patient with post pancreatectomy diabetes. $N$ Engl 7 . Med 1984;310:837-9.

3 Bilous $R W$, Poston $R N$, Keen H Viherti GC S wish, Poston RN, Keen H, Viberti GC, Serere diabetic microangiopathy with norm.

4 Bucher H, Zapf J, Torresani T, Prader A, Froesch ER, Illig R. Insulin like growth factors $\mathrm{I}$ and II, prolactin and insulin in 19 growth hormone deficien children with excessive, normal or decreased longitudinal growth after operation of craniopharyngioma. N Engl f. Med 1983:309:11+2-6.

5 Johnson TR, Blossey BK, Denko CW, Ilan J. Expression of insulin-like growth factor $I$ in cultured rat hepatocytes: effects of insulin and growth hormone. Molecular Endocrinologv 1989;3:580-7.

We thank $\mathrm{H}$ Dechaud for advice and growth hormone measurements.

\section{Surgery for detachment of the retina should not affect a normal delivery}

\author{
D V Inglesby, B C Little, A H Chignell
}

\section{Department of}

Ophthalmology,

St Thomas's Hospital,

London SE1 7EH

D V Inglesby, FRCS, senior

registrar

B C Little, FRCS, research

fellow

A H Chignell, FRCS,

consultant

Correspondence to:

Mr D V Inglesby,

Sunderland Eye Infirmary,

Sunderland, Tyne and Wear

SR2 9HP.

Br.Med f 1990;300:980 for it.

\section{Methods and results}

Both the obstetric experiences of some of our patients with detachment of the retina and inquiries from obstetricians about such patients drew our attention to the possible influence of this condition on obstetric practice. We had the impression that patients who had had surgery for retinal detachment were considered to be at high risk of a redetachment if they had a spontaneous vaginal delivery. We wanted to find out how prevalent this view was and review the evidence

Thirteen women who had had surgery for detachment of the retina over the past 10 years and subsequently had children were identified from the hospital records of 960 consecutive patients and a postal questionnaire. They had had a total of 16 deliveries. They were asked if they had had spontaneous deliveries or were assisted either with forceps or by caesarean section, and if either of the last two occurred was the reason "the eye" or "the baby"?

Forceps were used in four cases and a caesarean section was performed in one case because of the obstetricians' concern for the mother's retina. Thus intervention occurred in five of 16 deliveries because the mothers had had surgery for retinal detachment. There were no eye complications after the 16 deliveries.

A questionnaire was sent to 100 consultant obstetricians in England (13\% of the total number of consultants) chosen randomly from the Medical Directory, asking: "Do you consider that previous retinal surgery is ever an indication for the use of forceps or caesarean section or would such surgery not influence the obstetric care?" The choice of answers was "forceps," "section," or "no influence."

Eighty seven questionnaires were returned. Three quarters of the obstetricians replied that a history of surgery for detachment of the retina was an indication for obstetric intervention during labour (figure), although a few added that they had never seen such a case.

\section{Comment}

We could find no reference in current publications or in leading obstetric textbooks published over the past 60 years to support the belief that underlies this practice-namely, that spontaneous delivery is likely

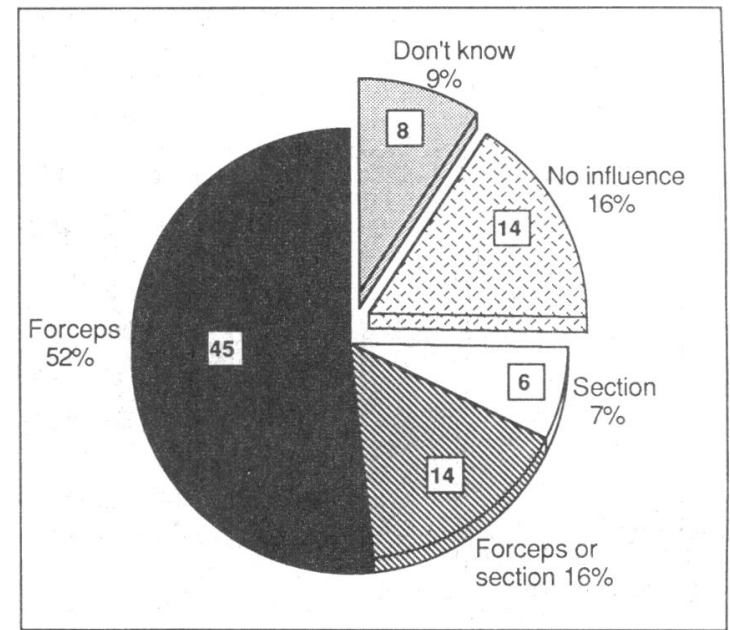

Responses from 87 consultant obstetricians to questionnaire on how they would manage deliveries in women who have had surgery for detachment of the retina

to precipitate redetachment of the retina in women who have had surgery for this condition. We think that this belief stems from the confusion between two types of retinal detachment, each of which has a distinct pathogenesis. Surgery is performed for retinal detachment when there is a break in the retina through which fluid passes into the subretinal space: a "rhegmatogenous" retinal detachment (Gk: rhegma=break). Detachment can also result from the exudation of fluid from beneath the retina when there is no break in the retina (a "serous" or non-rhegmatogenous retinal detachment), where the retina is lifted off from beneath by fluid.

A serous retinal detachment is not treated by surgery. This type of detachment is, however, known to obstetricians as it occurs in about a tenth of patients with eclampsia and in 1-2\% of patients with severe preeclampsia. ${ }^{1+4}$ In most patients the detachment fully resolves within a few weeks post partum. A history of surgery is thus implicit evidence of a previous rhegmatogenous detachment, and there is no reason why the physiological stresses of labour should increase the likelihood of redetachment in these women.

There is no clinical evidence or theoretical reason to support the widely held belief that previous surgery for detachment of the retina in the mother is a contraindication to a spontaneous vaginal delivery.

\footnotetext{
Mabie W', Ober RR. Fluorescein angiography in toxaemia of pregnancy. Brf Ophthalmol 1980;64:666-71.

2 Oliver $M$, Uchenik D. Bilateral exudative retinal detachment in eclampsia without hypertensive retinopathy. Am f Ophthalmol 1980;90:792-5.

3 Fry. WE. Extensive bilateral retinal detachment in eclampsia with complete re-attachment. Arch Ophthalmol 1929:1:609-14.

+ Hallum AV. Eye changes in hypertensive toxemia of pregnancv. $7 \mathrm{~A} .11 \mathrm{~A}$ 1936;106: 1649-51.

Accepted 11 fanuary 1990
} 